\title{
Investigation of Temporal and Spatial Variability for Green Tea Growth Using Precision Agriculture Technology*
}

\author{
Chanseok RYU*1, Masahiko SUGURI ${ }^{* 2}$, Mikio UMEDA ${ }^{* 3}$
}

\begin{abstract}
Spatial and temporal variability of new shoots (number of shoots, dry mass and nitrogen concentration) were investigated under several conditions using precision agriculture technology. The growth and spatial variability of new shoots were both determined using the normalized difference vegetation index (NDVI). At harvest, there were differences in new shoots growth depending on variety, severe shading, and nitrogen fertilizer type. There were differences in new shoot for "Ten-cya" compared to that for "Sen-cya," and temporal variability of growth had a different tendency compared to spatial variability at harvest depending on several conditions. Coefficients of determination $\left(\mathrm{R}^{2}\right)$ and root mean square error (RMSE) were established by the NDVI model. The accuracy was $\mathrm{R}^{2} \geq 0.826$ with $\mathrm{RMSE} \leq 15.0 \mathrm{~g} / \mathrm{m}^{2}$ for "Sen-cya" and $\mathrm{R}^{2} \geq 0.877$ with $\mathrm{RMSE} \leq 13.6 \mathrm{~g} / \mathrm{m}^{2}$ (vegetation coverage ratio $\leq$ $100 \%$ ) for "Ten-cya".
\end{abstract}

[Keywords] Spatial and temporal variability, new shoots, green tea, precision agriculture, NDVI model

\section{Introduction}

In Asia, tea is one of the value-added products in agriculture. In Japan, the production volume (PV) of tea which is mainly green tea, is $100,000 \mathrm{t} /$ year and it is the eighth largest PV in the world (FAO, 2008). There are three main brands of green tea: Shizuoka (41\% of PV), Kagoshima (18\% of PV) and Uji (3\% of PV) (MAFF, 2009). Although the $\mathrm{PV}$ in the Uji area is less than that in the other areas, the quality is the highest of all the Japanese teas. The amount of nitrogen fertilizer recommended for the green tea fields in this area is $638 \mathrm{~kg} / \mathrm{ha}$ (MAFF, 2000). However, more than 1000 $\mathrm{kg} / \mathrm{ha}$ is generally applied to improve the quality of green tea (Nagato, 2005). Due to the huge amount of nitrogen fertilizer applied in green tea fields, the environmental impact such as the acidification of rivers and reservoirs in certain areas in Japan has become an issue (Nakasone et al., 2004).

To control the amount of nitrogen fertilizer being used, it is necessary to identify the optimum plucking timing when the quantity and quality of tea are well balanced. The quality of tea negatively correlates with the quantity (Saba et al., 1993). The number of shoots (NS) and dry mass (DM) have been used as the standards for measuring quantity. Nitrogen concentration (NC), amino acid and crude fiber contents have been used as the standards for measuring quality (Goto et al., 1986, Horie et al., 1993, Smiechowska et al., 2006). However, these methods are destructive and time consuming.
Therefore, the rate of banjhi shoots, which is ratio of NS with opened needles to total NS, has been suggested as a standard of optimum plucking timing (Tanaka et al., 1989). However, it also takes a time to determine the banjhi shoot ratio and there exists spatial and temporal variability related to quantity and quality in the fields.

Therefore, it is necessary to identify the spatial and temporal variability of the growth for new shoots within a field and among different fields. Precision agriculture (PA) is a management practice made possible by the advent of suitable information technologies (Blackmore, 1994). In Japan, there are several approaches to investigate spatial and temporal variability of crops, using yields monitoring combine, GPS, GIS and RS (Umeda et al., 1999). NDVI (Makino et al., 2006) or ND index (Ishiguro et al., 2005) was suggested as a parameter to estimate the quantity and quality of green tea. However, in these studies, spatial and temporal variability was investigated in one field under the same condition. It is necessary to identify differences in the quantity and quality of green tea under different conditions.

The objectives of this research are 1) to investigate the quantity and quality of new shoots for green tea (NS, DM, and NC) using PA technology, 2) to compare the quantity and quality of new shoots under different conditions, and 3) to predict the quantity and quality of new shoots using NDVI and describe the spatial variability of DM in the fields.

* Presented at the $2^{\text {nd }}$ Asian Conference on Precision Agriculture in August 2007

*1 JSAM \& KSAM Member, Corresponding author, Graduate School of Agriculture Kyoto University, ShirakawaOiwake-Cho, Sakyo-Ku, Kyoto, 606-8502, Japan; ryu@elam.kais.kyoto-u.ac.jp

*2 JSAM Member, Graduate School of Agriculture Kyoto University, ShirakawaOiwake-Cho, Sakyo-Ku, Kyoto, 606-8502, Japan

*3 JSAM \& KSAM Member, Kyoto University, Yoshida Hon-machi, Sakyo-ku, Kyoto, 606-8501, Japan 


\section{Materials and Methods}

\section{Experimental fields}

The six tested fields were located at Wazuka-cho, in the Souraku-gun, Kyoto Prefecture, Japan (Table 1). New shoots (Camellia sinensis L.) of "Yabukita" and "Okumidori" were investigated to compare the difference in growth depending on the following conditions: 1) variety (fields A and B), 2) presence of severe shading (fields $\mathrm{C}$ and $\mathrm{D}$ ) and 3) type of nitrogen fertilizer used (fields $\mathrm{E}$ and F). The two fields in each group were adjacent to each other and managed by the same person. Although both chemical and organic nitrogen fertilizers are generally applied in the fields, in this study, organic nitrogen fertilizer was applied only in field E. Moreover, growth of new shoots for "Sen-cya", which needs a medium growth term without severe shading or with short severe shading just prior to harvest, was compared to that for "Ten-cya", which requires a long growth term under early severe shading. There were three sampling points in each field, except for field $\mathrm{A}$ that had five points. In field A and B, two sampling points were left to investigate the growth of new shoots after harvest.

\section{Measuring reflectance of green tea}

A portable crop growth information measuring apparatus (PCGIMA) was used to measure the reflectance of green tea. The device consisted of two sensor sets, each having three silicon photodiodes with spectral filters. The central wavelengths of the filters were $550 \mathrm{~nm}, 650 \mathrm{~nm}$ and $880 \mathrm{~nm}$ with $50 \mathrm{~nm}$ of half bandwidth. The upward set measured the incoming light intensity and the downward set measured the reflectance of the objects (Horio et al., 2002). Reflectance at each sampling point (within $300 \mathrm{~mm}$ in diameter) was measured at a height of $260 \mathrm{~mm}$. NDVI was calculated using the equation (1).

The reflectance of green tea in fields C, D, E, and F was measured at $1.5 \mathrm{~m}$ intervals by PCGIMA with DGPS BR-355 (GlobalSat, USA). The spatial variability maps were produced by the Krigging method of ArcGIS Desktop 9.1 (ESRI, USA).

Table 1. Information of experimental fields

\begin{tabular}{|c|c|c|c|c|c|c|}
\hline \multirow{2}{*}{ Group } & \multirow{2}{*}{ Field } & \multicolumn{3}{|c|}{ Location } & \multirow{2}{*}{$\begin{array}{l}\text { Shading } \\
\text { period }\end{array}$} & \multirow{2}{*}{$\begin{array}{c}\text { Type } \\
\text { (Variety) }\end{array}$} \\
\hline & & Gra & & & & \\
\hline & $\mathrm{A}$ & & & $\mathbf{m}$ & 5 days & Sen-cya $(Y)$ \\
\hline & B & 1 & 34. & $\mathrm{~m}$ & ys & Sen- \\
\hline & $\mathrm{C}$ & 135 & 34.7 & $249 \mathrm{~m}$ & 7 days & Sen-c \\
\hline & D & 135. & 34.7 & $260 \mathrm{~m}$ & 0 days & Sen-cya $(Y)$ \\
\hline & $\mathrm{E}$ & 135. & 34.7 & $360 \mathrm{~m}$ & 23 & Ten-cya $(\mathrm{Y})$ \\
\hline & $\mathrm{F}$ & $135.92^{\circ}$ & $34.78^{\circ}$ & $346 \mathrm{~m}$ & 26 days & Ten-cya(Y) \\
\hline
\end{tabular}

(Y: “Yabukita”, O: “Okumidori”)

$$
N D V I=\frac{R_{N I R}-R_{R E D}}{R_{N I R}+R_{R E D}}
$$

where $R_{N I R}$ and $R_{R E D}$ represent the reflectance from PCGIMA. The accuracy of the estimation model for the growth of new shoots was established using the coefficients of determination $\left(\mathrm{R}^{2}\right)$ and root mean square error (RMSE).

\section{Sampling of new shoots}

After measuring reflectance, new shoots that had more than "pekoe" (one needle with two leaves) in the frame, were plucked at each point and counted as NS. Samples were primarily parched for a few minutes using a microwave oven (500W) according to the amount. They were then dried with a circulation drier at $60^{\circ} \mathrm{C}$ for more than 24 hours and weighed as DM. NC of the finely grounded samples was measured using gas chromatography NC-900 (Sumica Chemical Analysis Service Ltd., Japan).

\section{Results and Discussions}

\section{Spatial and temporal variability}

(1) Number of shoots (NS)

NS increased with the growth of new shoots (Table 2). At harvest (Bold), there was no difference in NS depending on the variety $(\mathrm{p}=0.549)$ but there was a difference depending on the presence of severe shading $(\mathrm{p}=0.061)$. Although harvest timing differed, the presence of severe shading may have also influenced the difference in NS between fields C and D. Moreover, NS at harvest in field $\mathrm{E}$ was significantly different compared to that in field $\mathrm{F}(\mathrm{p}=0.051)$.

Table 2. Variation of the number of shoots during the first plucked term of new shoots

\begin{tabular}{ccccccc}
\hline $\begin{array}{c}\text { Number } \\
\text { of Shoots }\end{array}$ & \multicolumn{2}{c}{ Group 1 $(\mathrm{n}=5)$} & \multicolumn{2}{c}{ Group 2 } & \multicolumn{2}{c}{ Group 3 } \\
& $\mathrm{B}=3)$ & $\mathrm{C}(\mathrm{n}=3)$ & $\mathrm{D}(\mathrm{n}=3)$ & $\mathrm{E}(\mathrm{n}=3)$ & $\mathrm{F}(\mathrm{n}=3)$ \\
\hline April 20 & $6 \pm 3$ & & $16 \pm 4$ & $8 \pm 3$ & $19 \pm 5$ & $18 \pm 1$ \\
April 23 & $27 \pm 10$ & & $55 \pm 14$ & $32 \pm 8$ & $50 \pm 12$ & $49 \pm 1$ \\
April 27 & $65 \pm 18$ & & $80 \pm 14$ & $64 \pm 4$ & $57 \pm 1$ & $70 \pm 9$ \\
April 30 & $101 \pm 15$ & & $115 \pm 21$ & $132 \pm 14$ & $100 \pm 14$ & $113 \pm 6$ \\
May 3 & $133 \pm 21$ & & $\mathbf{1 3 5} \pm \mathbf{2}$ & $173 \pm 9$ & $107 \pm 22$ & $126 \pm 10$ \\
May 7 & $164 \pm 19$ & $51 \pm 5$ & & $\mathbf{1 6 5} \pm \mathbf{1 2}$ & $117 \pm 2$ & $144 \pm 7$ \\
May 9 & $\mathbf{1 6 6} \pm \mathbf{2 1}$ & $91 \pm 44$ & & & $119 \pm 20$ & $129 \pm 8$ \\
May 12 & $183 \pm 38$ & $134 \pm 31$ & & & $123 \pm 10$ & $149 \pm 29$ \\
May 14 & $177 \pm 26$ & $154 \pm 9$ & & & $110 \pm 12$ & $145 \pm 3$ \\
May 16 & $190 \pm 7$ & $158 \pm 18$ & & & $\mathbf{1 2 1} \pm \mathbf{1 2}$ & $\mathbf{1 4 6} \pm \mathbf{2 2}$ \\
May 19 & & $\mathbf{1 5 8} \pm \mathbf{1 1}$ & & & & \\
May 22 & & $171 \pm 13$ & & & & \\
\hline
\end{tabular}

(*: Mean \pm S.D., : shading, Bold: harvest, Red: after harvest) 


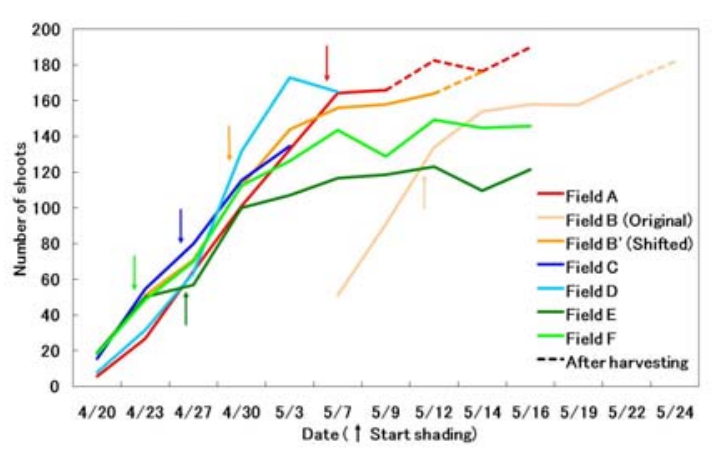

Fig. 1 Temporal variation for the number of shoots

In spite of the long growth term of "Ten-cya", NS of "Ten-cya" was significantly different compared to that of "Sen-cya" ( $p=0.019)$. However, the difference in NS was mainly influenced by NS in field $\mathrm{E}(\mathrm{p}=0.006)$ and not in field $\mathrm{F}(\mathrm{p}=0.345)$. In this study, the organic nitrogen fertilizer used with "Ten-cya" may have influenced the increase in NS.

The first sampling date in field B was shifted according to NS in the other fields to exclude the influence of variety (Fig. 1). NS increased with a similar slope toward the end of April regardless of the different growth conditions, after which the slope changed in "Sen-cya" and "Ten-cya". Early severe shading may have influenced the difference in NS of "Ten-cya". For "Sen-cya", the slope in field D showed a different tendency compared to those in fields $\mathrm{A}, \mathrm{B}$, and $\mathrm{C}$. The severe shading in fields A, B, and C may have acted as a brake on the controlling growth of NS (Aono et al., 1976).

Table 3. Variation for dry mass during the first plucked term of new shoots

\begin{tabular}{ccccccc}
\hline $\begin{array}{c}\text { Dry mass } \\
{\left[\mathrm{g} / \mathrm{m}^{2}\right]}\end{array}$ & $\mathrm{A}(\mathrm{n}=5)$ & $\mathrm{B}(\mathrm{n}=3)$ & $\mathrm{C}(\mathrm{n}=3)$ & $\mathrm{D}(\mathrm{n}=3)$ & $\mathrm{E}(\mathrm{n}=3)$ & $\mathrm{F}(\mathrm{n}=3)$ \\
\hline April 20 & $1.9 \pm 1.1$ & & $6.1 \pm 1.0$ & $3.2 \pm 0.9$ & $9.1 \pm 2.2$ & $8.1 \pm 0.3$ \\
April 23 & $11 \pm 4.7$ & & $26 \pm 6.5$ & $14 \pm 6.2$ & $27 \pm 6.3$ & $24 \pm 1.8$ \\
April 27 & $31 \pm 10$ & & $45 \pm 8.0$ & $34 \pm 6.6$ & $34 \pm 1.4$ & $38 \pm 7.5$ \\
April 30 & $52 \pm 10$ & & $73 \pm 10$ & $79 \pm 15$ & $66 \pm 10$ & $69 \pm 4.3$ \\
May 3 & $84 \pm 12$ & & $\mathbf{9 3} \pm \mathbf{3 . 4}$ & $119 \pm 17$ & $82 \pm 19$ & $88 \pm 8.6$ \\
May 7 & $125 \pm 12$ & $26 \pm 5.3$ & & $\mathbf{1 7 8} \pm \mathbf{1 8}$ & $124 \pm 9.2$ & $134 \pm 10$ \\
May 9 & $\mathbf{1 4 9} \pm \mathbf{2 9}$ & $\mathbf{6 4} \pm 23$ & & & $148 \pm 14$ & $159 \pm 16$ \\
May 12 & $192 \pm 16$ & $76 \pm 17$ & & & $175 \pm 13$ & $197 \pm 23$ \\
May 14 & $198 \pm 3.7$ & $86 \pm 12$ & & & $176 \pm 22$ & $194 \pm 8.7$ \\
May 16 & $229 \pm 23$ & $112 \pm 30$ & & & $\mathbf{2 2 5} \pm \mathbf{3 0}$ & $\mathbf{2 1 9} \pm \mathbf{1 4}$ \\
May 19 & & $\mathbf{1 1 4} \pm \mathbf{1 9}$ & & & & \\
May 22 & & $146 \pm 10$ & & & & \\
\hline
\end{tabular}

(*: Mean \pm S.D. , : : shading, Bold: harvest, Red: after harvest)

\section{(2) Dry mass (DM)}

DM of new shoots also increased with growth (Table 3). At harvest (Bold), there was no significant difference in DM depending on the variety (group $1, \mathrm{p}=0.211$ ). However, in group 2, there was a significant difference not only in NS but also in DM $(\mathrm{p}=0.020)$, which means that no shading may increase not only NS but also DM. There was no difference in $\mathrm{DM}$ in group 3 ( $\mathrm{p}=0.582$ ), but there was a difference in NS, which means that DM of new shoots in field $\mathrm{E}$ was heavier than that in field F. When DM in each field was compared, DM of "Ten-cya" at harvest was heavier than that of "Sen-cya" $(p<0.022)$. Although the shading condition was different for "Ten-cya" and "Sen-cya", the growth period may have also influenced the difference in DM, because DM after harvest in field A (Red) was similar to that in fields $\mathrm{E}$ and F.

Until the end of April, the slope of DM was similar to each other in spite of the different conditions, but it changed from the beginning of May (Fig. 2). Although DM at harvest was not significantly different for group 1, the slope of growth in fields A and B was different from the beginning of May. The slope of DM in fields A, C, E, and F was similar, but DM at harvest was significantly different between "Sen-cya" and "Ten-cya". Thus, the increase in DM may be influenced not only by the variety but also by the presence of severe shading.

\section{(3) Nitrogen concentration (NC)}

On April 20, NC in fields A, E, and F could not be measured because of insufficient amounts (Table 4). There was a significant difference in $\mathrm{NC}$ at harvest (Bold) depending on the variety $(\mathrm{p}=0.018)$ and presence of severe shading $(\mathrm{p}=0.015)$; however, there was no difference depending on the type of nitrogen fertilizer $(\mathrm{p}=0.683)$. Variety and presence of severe shading may control $\mathrm{NC}$ of new shoots at harvest. Moreover, NC of "Ten-cya" was less than that of "Sen-cya" ( $<<0.065)$, except in field D $(p>0.350)$; therefore, $\mathrm{NC}$ may be influenced by the growth period with severe shading, because NC after harvest in field A ("Sen-cya") was decreased as much as NC in "Ten-cya".

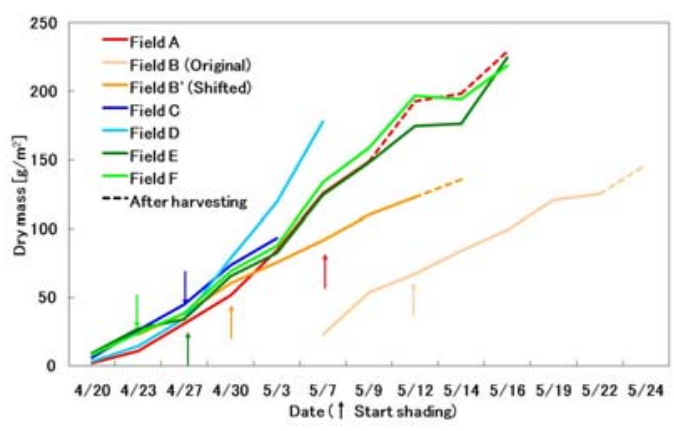

Fig. 2 Temporal variation of dry mass 
Table 4. Variation of nitrogen concentration during the first plucked term of new shoots

\begin{tabular}{ccccccc}
\hline \multirow{2}{*}{$\begin{array}{c}\text { Nitrogen } \\
{[\%]}\end{array}$} & \multicolumn{2}{c}{ Group 1 } & \multicolumn{2}{c}{ Group 2 } & \multicolumn{2}{c}{ Group 3 } \\
\cline { 2 - 7 } & $\mathrm{A}(\mathrm{n}=5)$ & $\mathrm{B}(\mathrm{n}=3)$ & $\mathrm{C}(\mathrm{n}=3)$ & $\mathrm{D}(\mathrm{n}=3)$ & $\mathrm{E}(\mathrm{n}=3)$ & $\mathrm{F}(\mathrm{n}=3)$ \\
\hline April 20 & $\cdot$ & & $5.6 \pm 0.1$ & $5.3 \pm 0.2$ & $\cdot$ & $\cdot$ \\
April 23 & $5.8 \pm 0.2$ & & $5.8 \pm 0.0$ & $5.7 \pm 0.2$ & $5.6 \pm 0.1$ & $5.7 \pm 0.2$ \\
April 27 & $5.6 \pm 0.1$ & & $5.9 \pm 0.0$ & $5.6 \pm 0.1$ & $5.6 \pm 0.2$ & $6.0 \pm 0.2$ \\
April 30 & $5.7 \pm 0.1$ & & $6.4 \pm 0.2$ & $5.5 \pm 0.1$ & $6.0 \pm 0.1$ & $6.2 \pm 0.2$ \\
May 3 & $5.7 \pm 0.1$ & & $\mathbf{6 . 4 \pm 0 . 2}$ & $5.6 \pm 0.1$ & $6.0 \pm 0.1$ & $6.1 \pm 0.0$ \\
May 7 & $5.7 \pm 0.1$ & $5.6 \pm 0.0$ & & $\mathbf{5 . 4 \pm 0 . 0}$ & $5.8 \pm 0.1$ & $5.8 \pm 0.3$ \\
May 9 & $\mathbf{5 . 5 \pm \mathbf { 0 . 2 }}$ & $5.8 \pm 0.0$ & & & $5.6 \pm 0.1$ & $5.4 \pm 0.2$ \\
May 12 & $5.3 \pm 0.1$ & $5.9 \pm 0.1$ & & & $5.5 \pm 0.2$ & $5.4 \pm 0.2$ \\
May 14 & $5.4 \pm 0.2$ & $6.2 \pm 0.1$ & & & $5.2 \pm 0.1$ & $5.1 \pm 0.3$ \\
May 16 & $5.1 \pm 0.3$ & $6.1 \pm 0.3$ & & & $\mathbf{5 . 2 \pm 0 . 2}$ & $\mathbf{5 . 2 \pm 0 . 3}$ \\
May 19 & & $\mathbf{5 . 9 \pm 0 . 1}$ & & & & \\
May 22 & & $6.1 \pm 0.2$ & & & & \\
\hline
\end{tabular}

(*: Mean \pm S.D., : : shading, Bold: harvest, Red: after harvest)

The decrease in NC in fields $\mathrm{A}$ and $\mathrm{D}$ with the growth of new shoots may be influenced by the presence and timing of severe shading, i.e., no shading in field $\mathrm{D}$ and late shading in field A (Fig. 3). In the case of early severe shading (fields C, $\mathrm{E}$, and F), NC increased with early severe shading and decreased depending upon the period of severe shading (Tanaka et al., 1989). Although there was a difference in NC between "Sen-cya" and "Ten-cya", NC in fields A, E, and F was similar from May 7, when NC after harvest in field A was included. This suggests that NC in "Sen-cya" may decrease if "Sen-cya" was harvested as late as "Ten-cya".

\section{Estimation model using NDVI}

In each field, NDVI significantly correlated with NS and $\mathrm{DM}$, except for $\mathrm{DM}$ in field $\mathrm{E}$ (Table 5). Although $\mathrm{NC}$ in fields $\mathrm{A}, \mathrm{B}, \mathrm{D}$, and $\mathrm{E}$ correlated with NDVI, the correlation tendency was different for each field. Moreover, there was a significant correlation between NDVI and total NS and between NDVI and total DM.

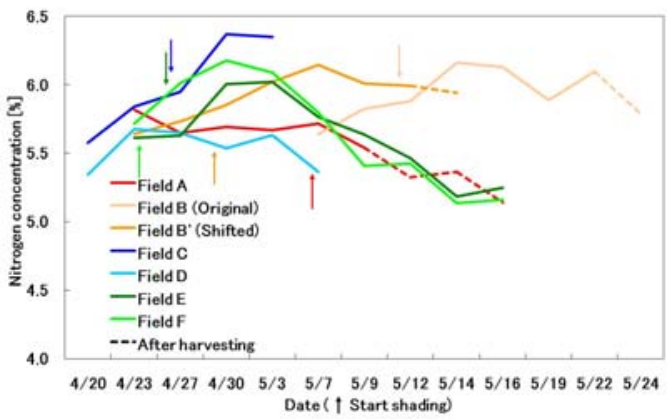

Fig. 3 Temporal variation of nitrogen concentration
Table 5 Correlation coefficient between NDVI and growth of shoots

\begin{tabular}{ccccccc}
\hline \multirow{2}{*}{ NDVI } & \multicolumn{2}{c}{ NS } & \multicolumn{2}{c}{ Dry mass } & \multicolumn{2}{c}{$\mathrm{NC}$} \\
\cline { 2 - 7 } & $\mathrm{n}$ & $\mathrm{r}$ & $\mathrm{n}$ & $\mathrm{r}$ & $\mathrm{n}$ & $\mathrm{r}$ \\
\hline $\mathrm{A}$ & 41 & $0.910^{* *}$ & 41 & $0.909^{* *}$ & 36 & $-0.454^{* *}$ \\
$\mathrm{~B}$ & 20 & $0.882^{* *}$ & 20 & $0.912^{* *}$ & 20 & $0.398^{*}$ \\
$\mathrm{C}$ & 18 & $0.898^{* *}$ & 18 & $0.991^{* *}$ & 18 & -0.187 \\
$\mathrm{D}$ & 25 & $0.891^{* *}$ & 25 & $0.930^{* *}$ & 15 & $0.873^{* *}$ \\
$\mathrm{E}$ & 27 & $0.668^{* *}$ & 27 & 0.281 & 24 & $0.422^{* *}$ \\
F & 29 & $0.794^{* *}$ & 29 & $0.591^{* *}$ & 26 & 0.006 \\
Total & 150 & $0.674^{* *}$ & 150 & $0.692^{* *}$ & 139 & 0.055 \\
\hline (*.5\% of significance level, $* * .1 \%$ of significance level) &
\end{tabular}

However, there was no significant correlation between NDVI and total $\mathrm{NC}$, because of the different correlation tendencies and narrow variation of $\mathrm{NC}$.

DM after harvest was excluded to show the accuracy of each estimation model in "Sen-cya" because the correlation between NDVI and DM changed to negative when NDVI was more than 0.850 (Fig. 4). $\mathrm{R}^{2}$ and RMSE were 0.922 and 15.0 $\mathrm{g} / \mathrm{m}^{2}$ (field A), 0.826 and $14.1 \mathrm{~g} / \mathrm{m}^{2}$ (field B), 0.864 and 11.7 $\mathrm{g} / \mathrm{m}^{2}$ (field C), and 0.982 and $8.49 \mathrm{~g} / \mathrm{m}^{2}$ (field D), respectively. However, the distribution of $\mathrm{DM}$ in field $\mathrm{C}$ was different; therefore, the data in field $\mathrm{C}$ was excluded to construct a general purpose model that might be capable of estimating DM regardless of the changes in environmental variables and conditions (Ryu et al., 2009). The accuracy of the general purpose model was determined as $\mathrm{R}^{2}=0.874$ with $\mathrm{RMSE}=18.7$ $\mathrm{g} / \mathrm{m}^{2}$. Although this accuracy was less than that of each estimation model, it was possible to estimate DM of "Sen-cya" regardless of the different conditions.

For "Ten-cya", although DM increased according to the growth of new shoots, NDVI decreased after initially increasing with growth (Fig. 5). Thus, DM of "Ten-cya" was separated into two parts depending on VCR which was approximately $100 \%$ on May 9 . When VCR was less than $100 \%$, the accuracy was $\mathrm{R}^{2}=0.887$ with $\mathrm{RMSE}=13.6 \mathrm{~g} / \mathrm{m}^{2}$ (field $\mathrm{E}$ ) and $\mathrm{R}^{2}=0.877$ with $\mathrm{RMSE}=11.9 \mathrm{~g} / \mathrm{m}^{2}$ (field F).

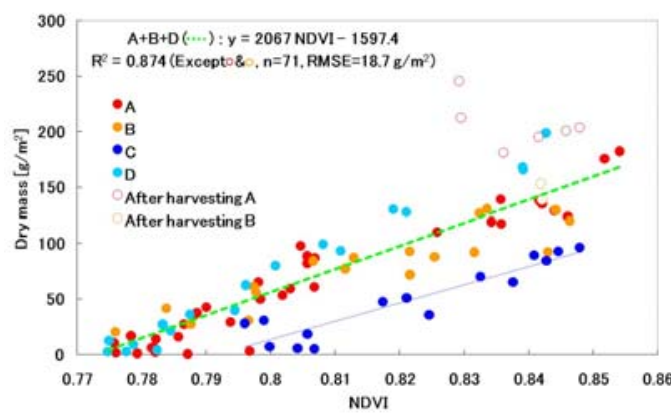

Fig. 4 Scatter plots of NDVI and dry mass in "Sen-cya" 


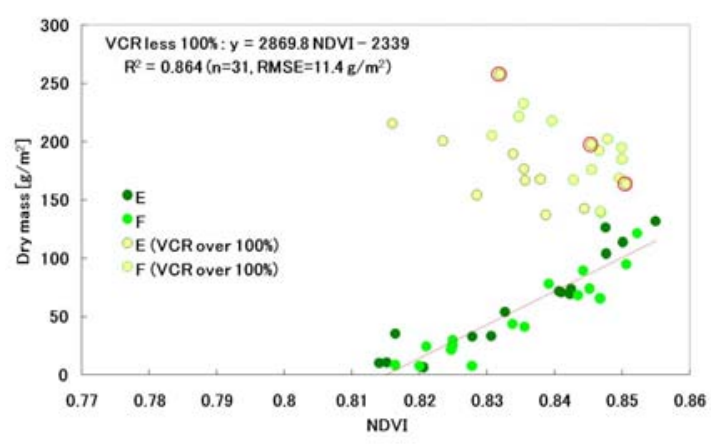

Fig. 5 Scatter plots of NDVI and dry mass in "Ten-cya"

The accuracy of the general purpose model for DM at the growth stage ( $\mathrm{VCR} \leq 100 \%)$ was $\mathrm{R}^{2}=0.864$ with $\mathrm{RMSE}=14.0$ $\mathrm{g} / \mathrm{m}^{2}$. However, it was necessary to estimate DM for the harvest as well, and it was not possible to estimate DM in field $\mathrm{E}$ because there was no significant correlation. Therefore, three DMs within the red circle in Fig. 5 were excluded. The accuracy of the modified model was $\mathrm{R}^{2}=0.662$ with $\mathrm{RMSE}=14.3 \mathrm{~g} / \mathrm{m}^{2}$ (field $\mathrm{E}$ ) and $\mathrm{R}^{2}=0.354$ with $\mathrm{RMSE}=22.5$ $\mathrm{g} / \mathrm{m}^{2}$ (field F).

When Fig. 4 and Fig. 5 were considered simultaneously, NDVI started around 0.775 in "Sen-cya" and around 0.815 in "Ten-cya", which means that the slope of the NDVI model in field C may be between that of "Sen-cya" and "Ten-cya". Although the reason why the slope of the model in field $\mathrm{C}$ occurred in this way was not definitively determined, early severe shading may be one of the reasons. If a general purpose model for growth of new shoots is estimated, it may be possible to manage the growth of new shoots by the timing and period of severe shading and variable rate of fertilizer application.

\section{Spatial variability}

The spatial variability of DM for each field was investigated using the estimation model mentioned previously. However, it was difficult to analyze the spatial variability of DM in fields $\mathrm{E}$ and $\mathrm{F}$, because the precision of the kigging method and the accuracy of the model were low (Fig. 6). DM in field F may be overestimated because of the low accuracy of the model. $\mathrm{DM}$ in the northern part of fields $\mathrm{E}$ and $\mathrm{F}$ was better than in other parts. Although there was sufficient DM at low altitudes in fields $\mathrm{C}, \mathrm{E}$, and partially in $\mathrm{F}$, an opposite result was obtained in field D. Thus, it is necessary to identify the spatial variability of DM to manage the growth of new shoots as uniformly as possible.

Although it is possible to estimate the quantity (DM) and analyze spatial variability using NDVI, it was difficult to estimate the quality (NC).

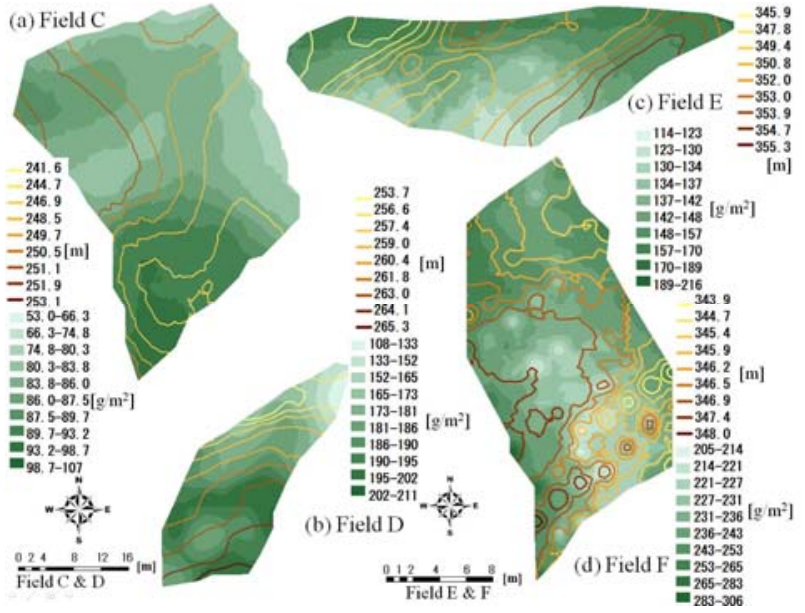

Fig. 6 Spatial variability of dry mass before harvest

Therefore, it is necessary to analyze $\mathrm{NC}$ with a hyperspectral camera or spectroscope to estimate NC in the shoots (Ryu et al., 2010). When the market price and the quantity and quality of tea are predicted on the basis of the estimation model, it may be possible to calculate the optimum plucking timing. Once the optimum plucking timing is established, it may be possible to calculate the optimum amount of nitrogen fertilizer necessary to minimize the environmental impact such as the acidification of rivers and reservoirs.

\section{Summary and Conclusions}

The spatial and temporal variability of new shoots for green tea under several conditions was investigated using PA technology. The growth and spatial variability of new shoots were determined by the NDVI model.

NS and DM increased with the growth of new shoots, but NC showed a different pattern. At harvest, there was no significant difference in NS depending on the variety (group 1 , fields A and B) but there was a significant difference depending on the presence of severe shading (group 2, fields $\mathrm{C}$ and D) and type of nitrogen fertilizer (group 3, fields E and F). In spite of the long growth term under early severe shading, NS of "Ten-cya" was significantly different than that of "Sen-cya", not because of NS in field F but because of NS in field E. NS increased with a similar slope regardless of the different conditions and then changed depending on severe shading.

There was a significant difference in DM at harvest for group 2, but not for groups 1 and 3. Moreover, DM of "Ten-cya" was heavier than that of "Sen-cya" because of the growth period. Therefore, the change in the slope of DM in the three groups may be influenced not only by the variety but also by the presence of severe shading. 
Significant differences in NC were found in groups 1 and 2, but not in group 3. Moreover, NC of "Ten-cya" was less than that of "Sen-cya" because of the growth period under severe shading. The slope of NC was influenced by the presence as well as the timing of severe shading.

NDVI had significant correlations with NS and DM, but only a partial correlation with NC. In the estimation model for DM of "Sen-cya", the accuracy was $\mathrm{R} \geq 0.826$ with $\mathrm{RMSE} \leq 15.0 \mathrm{~g} / \mathrm{m}^{2}$. The accuracy of a general purpose model was $\mathrm{R}^{2}=0.874$ with $\mathrm{RMSE}=18.7 \mathrm{~g} / \mathrm{m}^{2}$. The accuracy of the "Ten-cya" model, which was less than $100 \%$ of the VCR, was $\mathrm{R}^{2} \geq 0.877$ with $\mathrm{RMSE} \leq 13.6 \mathrm{~g} / \mathrm{m}^{2}$. It was difficult to estimate the general purpose model; however, it was possible to show the spatial variability of DM for each field using the estimation model.

\section{Acknowledgements}

In this regard, we would like to express our thanks to Mr. Sugimoto, Mr. Hata, and Mr. Hayashi, who made an offer the experimental fields.

\section{References}

Aono, H., Y. Yanase, S. Tanaka and S. Sugii. 1976. Use of chemical fibre cloths as the artificial shading materials in tea cultivation. Bull. Vegetable \& tea Exp. Stn. 12:1-123. (in Japanese)

Blackmore, S. 1994. Precision farming: An introduction. Outlook on Agriculture, 23(4), 275-280

Goto, T., T. Shibata and Y. Yamaguchi. 1990. Sequential change of the contents of total nitrogen and neutral detergent fiber in tea shoots. Bull. Shizuoka Tea Exp. Stn. 15:43-47. (in Japanese)

Goto, T., J. Uozumi and T. Suzuki. 1986. Near infrared spectroscopic analysis of total nitrogen content in green tea "Sen-cha". Bull. Shizuoka Tea Exp. Stn. 12:61-68. (in Japanese)

Horie, H., S. Fukatsu, T. Mukai, T. Goto, M. Kawanaka and T. Shimohara. 1993. Quality evaluation on green tea. Sensors and Actuators B, 13-14:451-454.

Horio, M., Y. Nishimura, T. Ichigawa, K. Hayashi, T. Goto, K. Iizuka, H. Tanaka and Y. Okunishi. 2002. Development of handy-type crop growth measuring device. Japanese Journal of crop science, 71(2), 126-127. (in Japanese)

Ishiguro, E., Ishikawa, D., Kuroiwa, S., Sato, M., Yoshitomi, H., Takeda, Y. 2005. Study of tea plant growing conditions with spectral reflectance. Journal of Agric. Methorol. 60(5):929-932.

Luypaert, J., M. H. Zhang and D. L. Massart. 2003. Feasibility study for the use of near infrared spectroscopy in the qualitative and quantitative analysis of green tea, Camellia sinensis(L.). Analytica Chimica Acta. 478:303-312
MAFF. 2000. The standard of fertilizer application for each prefecture. (in Japanese) http://www.maff.go.jp/sehikijun/top.html.

MAFF. 2009. The cultivation area of the green tea field for each prefecture. (in Japanese)

http://www.maff.go.jp/www/info/bunrui/mono04.html.

Makino, Y., M. Umeda and C. S. Ryu. 2006. Measurement of quality and quantity of green tea using remote sensing. Kansai Branch Report of JSAM 99:102-105. (in Japanese)

Nagato, W. 2005. Influence of the uniform reduction of nitrogen fertilizer on the new shoots of tea plants. Exp. Bull. Kanagawa Stn. 147:23-30. (in Japanese)

Nakasone, H., and T. Yamamoto. 2004. The impacts of the water quality of the inflow water from tea fields on irrigation reservoir ecosystems. Paddy water Enviro. 2:45-50

Tanaka, S., K. Iwasa, S. Fukatsu, H. Aono, S. Tanaka and T. Saba. 1989. Relationship between plucking time and the quality of green tea. Bull. Vegitable \& tea Exp. Stn. B (kanetani) 3:55-64. (in Japanese)

Ryu, C. S., M. Suguri and M. Umeda. 2009. Model for predicting the nitrogen content of rice at panicle initiation stage using data from airborne hyperspectral remote sensing. Biosystems Engineering 104:465-475.

Ryu, C. S., M. Suguri and M. Umeda. 2010. Estimation of the quantity and quality of green tea using hyperspectral sensing, Journal of JSAM 72(1):46-53. (in Japanese)

Saba, T., H. Aono and S. Tanaka. 1993. Methods for the estimation of optimum plucking time in reration to tea quality based on the characteristics of new shoots of tea plants. Bull. Vegitable \& tea Exp. Stn. B (Tea Exp.) 6:11-20. (in Japanese)

Smiechowska, M. and P. Dmowski. 2006. Crude fibre as a parameter in the quality evaluation of tea. Food chemistry 94:366-368.

Umeda, M., T. Inamura, T. Kosaki, Y. Shibata and Y. Jara. 1999. Technology in the $21^{\text {st }}$ century. Journal of JSAM 61(4):4-23. (in Japanese)

(Received: 23. February. 2010, Accepted: 23. August. 2010) 